\title{
Smart Integrated Multiple Tracking System Development for IOT based Target-oriented Logistics Location and Resource Service
}

\author{
Ju-Su Kim, Hak-Jun Lee and Ryum-Duck Oh ${ }^{*}$ \\ Dept. of Software, Korea National University of Transportation, Korea, \\ \{dorek99, jsy3589\}@naver.com,rdoh@ut.ac.kr, *CorresPonding Author
}

\begin{abstract}
With the rapid development of the IoT market many institutions are researching and developing various integrated IOT service platforms. Among them the development of IoT based tracking system requires a platform environment that can check in real time the target-oriented logistics movement status in industrial sites and social environments and manage resources. Previous related researches studied about particular single object tracking and about establishing a linkage process, but there were no studies about systems using Multiple Tracking System that target a variety of objects to establish a total task process such as for materials, personnel, and operations and process management. The study developed an efficient target-oriented smart integrated multiple tracking system that looks up object location based on real time and guarantees the accuracy and reliability of logistics location and resource management by combining the function of multiple tracking system.
\end{abstract}

Keywords: IoT, Tracking System, RLBS, LBS, GPS, RFID

\section{Introduction}

Currently, developed countries and companies are paying attention to the IoT (Internet of Things) era. With the expansion of the service market through integration with various industries IoT market is rapidly growing and there are many researches being done about tracking systems using IoT technology.

Tracking system observes location information about object or human movement and supply and it is widely used in many fields such as logistics industry, electronic commerce, and military purposes. Recently due to the development of tracking system and IoT technology ubiquitous approach of human life around human life is being actively conducted and is applying level of IT technology that can continuously check and manage field status in all social environments and industrial fields [1].

Tracking systems can be used expanded to the purposes such as automation system establishment in distribution/logistics field, cost savings through establishment of efficient task process, resource management for profit maximization, personnel management, and task management. The representative technologies for this are GPS, RFID, Sensor, LAN, Wireless-Network, and WiFi

Among the many technologies used in tracking system the representative technologies are GPS and RFID. GPS (Global Positioning System) which is a positioning system receives wireless signals from satellites to measure location and there is no need to establish additional infrastructure for wide area location measurement so there are many advantages in the physical/temporal sense [2]. RFID technology is a new age contactless technology that can be expanded to a maximum of 27 meters, and it is able to penetrate through barricades excluding metals and it is 
currently in the spotlight because it is not limited to the information and communication field and because can be applied to various fields such as logistics, distribution, supply chain, transportation, and environment [3].

Also in addition to development of wireless Internet Technology and rapid development of mobile terminal device technology, Location Based Services, LBS is largely increasing. Accordingly, location recognition technology has become an essential factor in providing these services, and through integrating tracking system there is need for this type of location measurement technology in many applications such as prevention of lost children and freight tracking $[4,5]$.

Therefore the study uses GPS, RFID, LAN, Wireless-network, and WiFi technology to establish a Real-Time Tracking System based on RLBS(Real-Time Location Based Service) and suggests Smart integrated multiple tracking system. Based on the suggestion the study suggests a smart integrated multi tracking system that can manage and supervise on the field and remotely through daily task scheduling and check sheets at the Distribution / Logistics / Construction field, which can increase task efficiency through material supply in discharge management, and which can strengthen competitiveness.

\section{Related Research}

To develop an integrated multi tracking system the study conducted investigation on the problems the previous system had through establishment of development plan and information research, and to solve the corresponding limitations the study conducted research on developing smart integrated tracking system based on IoT, RTLS, and RFID.

In Proceeding of The Korean Institute of Maritime Information Communication Sciences a research was done about managing such things as the quantity of goods loaded, product information, delivery status, and missing item status, and managing web of goods distribution process by receiving location information from GPS then linking information such as Real-Time location information about the goods loaded, distribution path, and area of production with Google Maps [6].

According to M.S. Theses there was a research for efficient management of containers in container storage yards through using location tracking techniques using GPS and using Wireless Data communication technique to enable through interface module checking of vehicle location on maps [7].

There was research on managing resources according to task function and process by linking PDA and PMIS systems with wireless, checking work location of the site through attached RFID information on each material, figuring out materials management flow in the construction factory using RFID, and by analyzing current material management process [8].

There was research on establishing a system that figures out information by attaching RFID based RTLS tags for indoor location positioning with previous tracking system and monitors in Real-Time the location of an object using GPS in outdoor location[9].

tracking system related research about using RTLS (Real Time Location System) rather than GPS to attach tags on objects or things to track location in RealTime[10].

There was research about a tracking system that manages distribution process of goods by managing product information of the goods loaded onto vehicles, quantity, and delivery status, and linking information with Google Maps such as Real-Time production area, location information, and distribution path by receiving GPS information from vehicles $[11,12]$. 
There was research that enabled checking the location of vehicles through interface module as a location tracking technique utilizing GPS and Wireless Networks for efficient container management in harbor Container Storage yards based on logistics support system [13].

\section{System Configuration of Smart Integrated Multi Tracking System}

The study developed Smart integrated multiple tracking system which is a system that manages and supervises personnel and material at logistics companies and intelligently tracks location of goods that remotely manages and supervises on site personnel and work status through task scheduling and check sheet and increases task efficiency through management of stocking and shipment of goods.

The system largely consists of integrated collection server for DB construction and data analysis, integrated administrator PC for attendance management and report management, goods management PC for goods management, and mobile device for task management. The main functions are attendance management, goods management, task management, and report management. Figure 1 shows the configuration of the Smart Integrated Multi Tracking System.

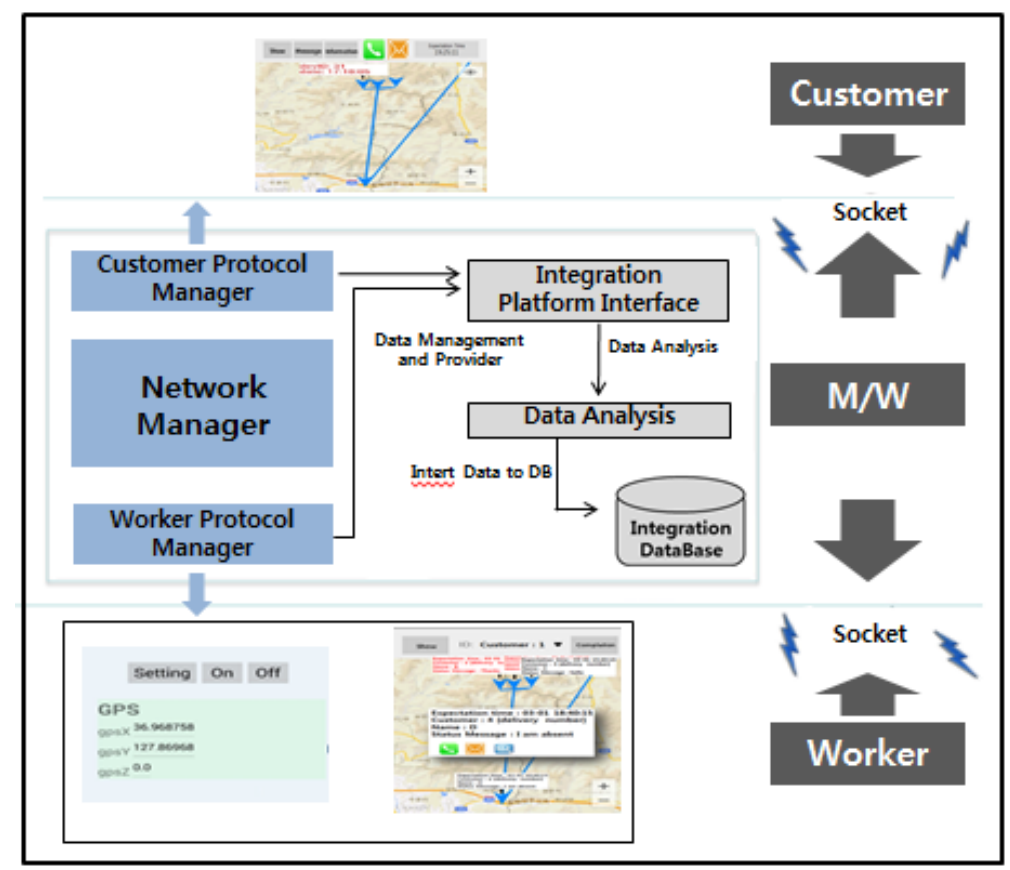

Figure 1. The Operating Procedure Diagram on Collection Server

\subsection{Integrated Object Movement Information Collection Server}

At the collection server onsite work status is received from onsite worker mobile device, collects warehouse history from inventory management PC and sends inventory shipping history. Also databases about inventory management, onsite work management, and worker management information are established, and the server is composed of worker schedule management server, report information collection server, and GPS information collection server. The block diagram of collection server is represented by Figure 2, and the flow chart is represented by Figure 3. 


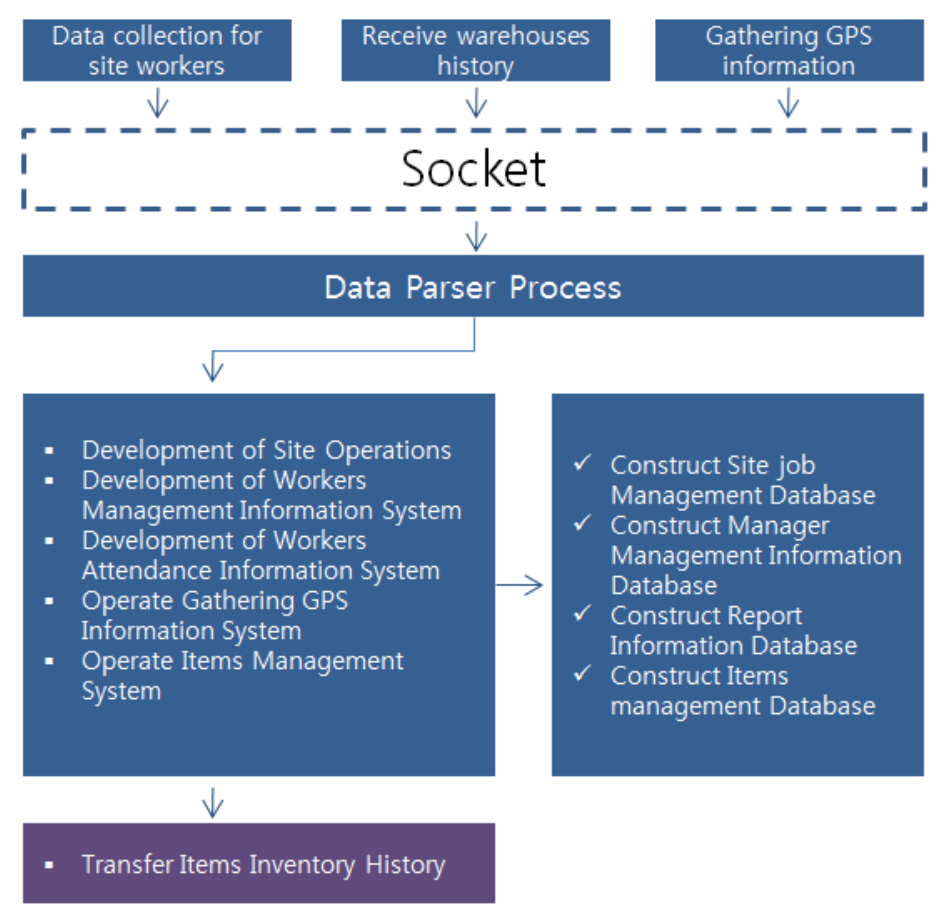

Figure 2. The Structure of Integrating Collection Server

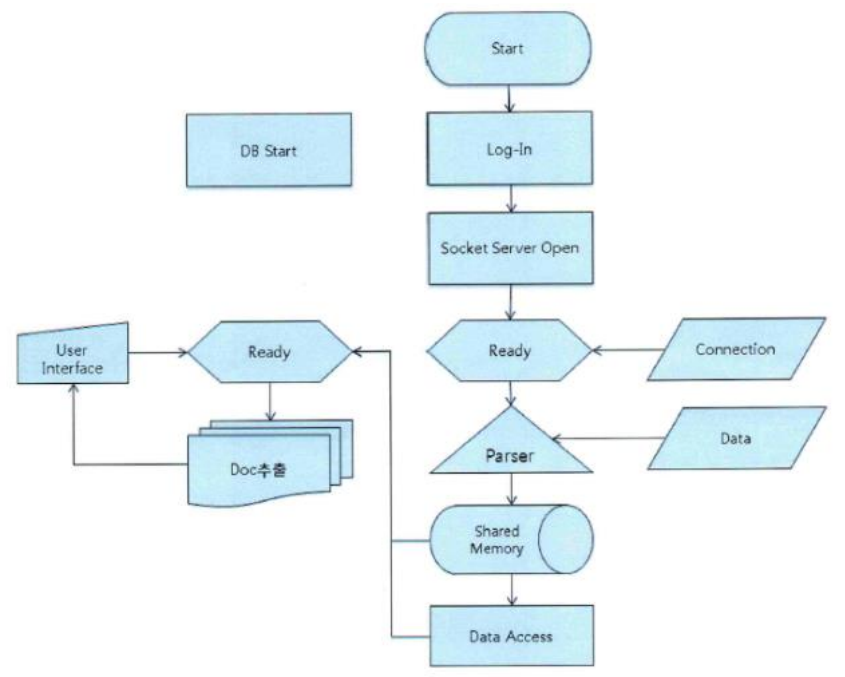

Figure 3. The Operating Procedure of Collection Server

\subsection{Integrated Operations Manager Perspective Task}

Administrator PC that conducts attendance management and report management functions is composed of worker attendance and management information monitoring program, work management status monitoring program, materials management status monitoring program, Open GIS based worker location monitoring program, attendance management device communication program, and worker registration management program. GPS information tracking program operation flow chart is represented by Figure 4. 


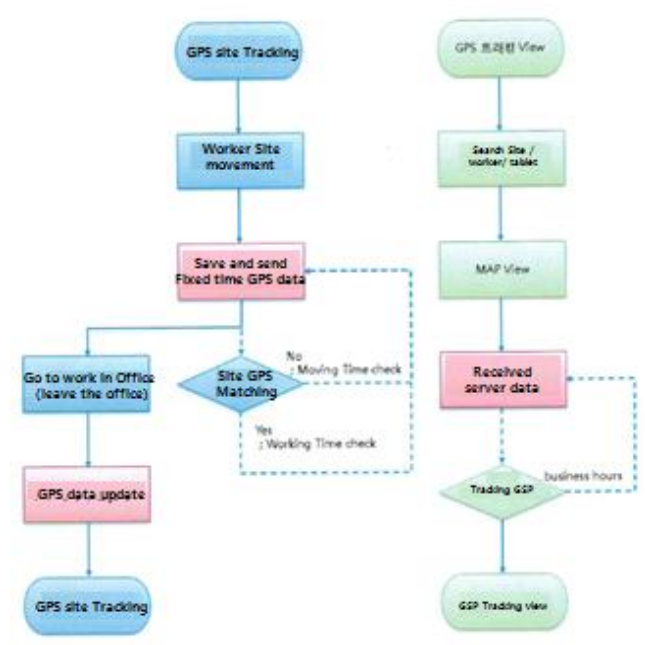

Figure 4. GPS Information Tracking Operation

\subsection{Integrated Inventory Management Perspective Task}

Integrated inventory management $\mathrm{PC}$ that performs inventory management function is composed of inventory management status monitoring program, inventory collections and payments management program, inventory management program for mobile tablets, and barcode reader communication program. Figure 5 represents the integrated inventory management perspective task configuration.

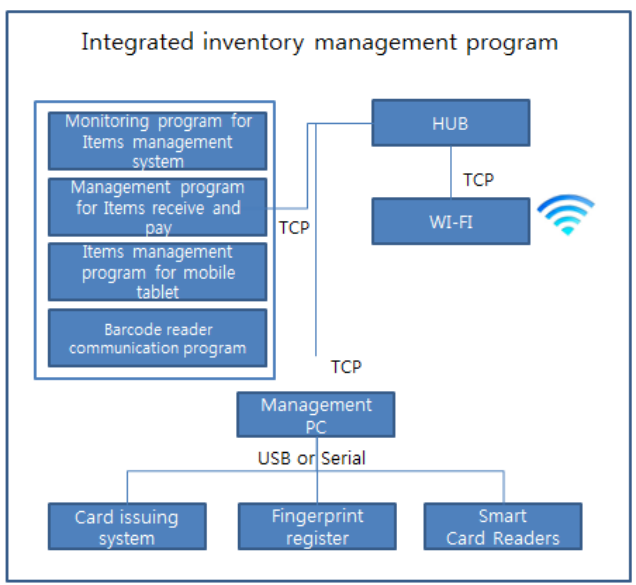

Figure 5. Task Configuration as View of Integrated Inventory Management

\subsection{Mobile Device Operating Procedures}

Mobile device is composed of inventory usage management app program, GPS communication program, remote data transmission program using WCDMA communication, worksite photo information collection and server transmission program, barcode reader communication program, worker management and Log-In/Out program, and daily checklist writing app program for reports. Figure 6 represents the mobile device app module operation algorithm. 


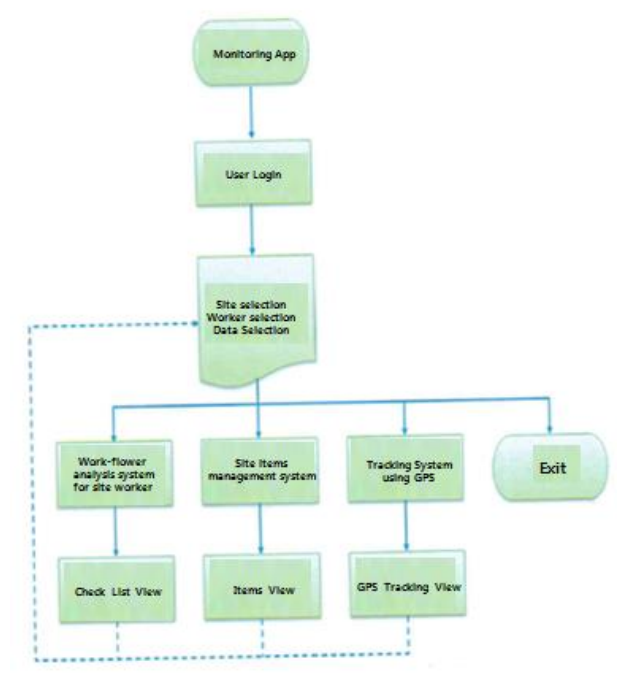

Figure 6. Operation Algorithms on the Mobile Device App

\section{Configuration and Function of Smart Integrated Multi Tracking System UI}

Figure 7 represents the composition of main UI and because there are menus such as worker management, attendance management, inventory management, and GIS, it is possible to monitor integrated multi tracking.

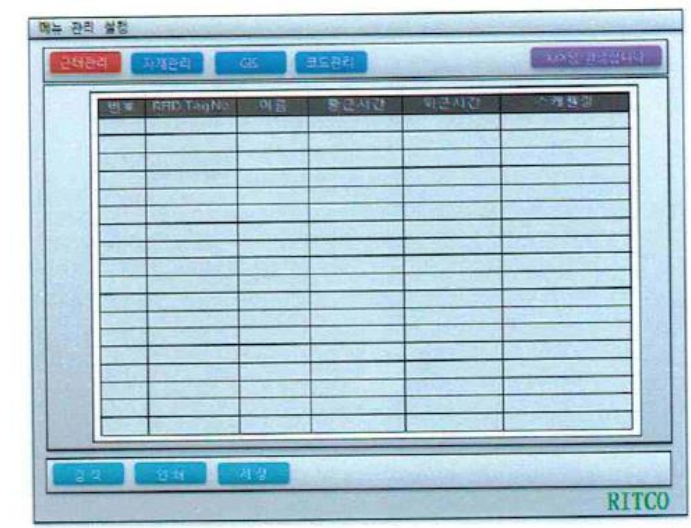

\section{Figure 7. The UI Structure of Multi Tracking System}

\subsection{Integrated Administrator Perspective Client Configuration}

The integrated administrator PC program enables remote work instruction to workers and by using the drop down view by date, site, and manager it can simultaneously monitor workers through multi tracking and it is possible to monitor detailed content of such things as manager work time, movement path, and allocated work. Figure 8 is the UI configuration of integrated administrator program. 


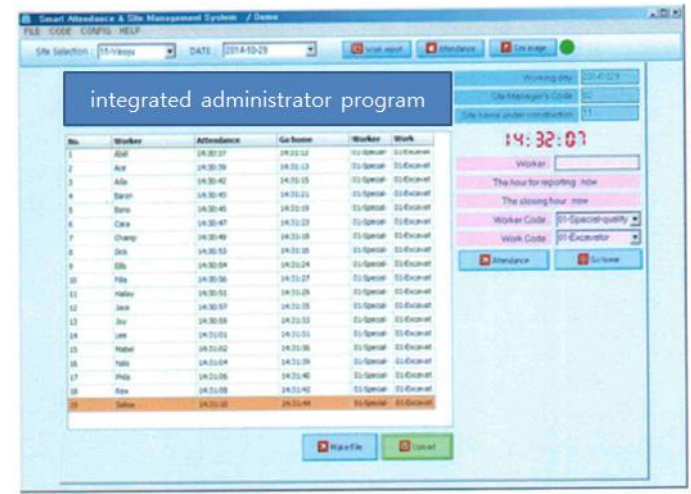

Figure 8. UI Configuration for Integrated Administrator

\subsection{Integrated Inventory Management Perspective Client Configuration}

Integrated inventory management program enables tracking movement path of inventory within warehouse, and by using drop down view, by date, site, and characteristic can see simultaneously various inventory detailed status or location through multi tracking, and can check detailed functions such as future inventory predicted movement path and inventory sticking and shipping predicted dates, and also by linking with integrated worker PC program it can allocate inventory to the worker. Figure 9 represents the integrated inventory management program UI configuration.

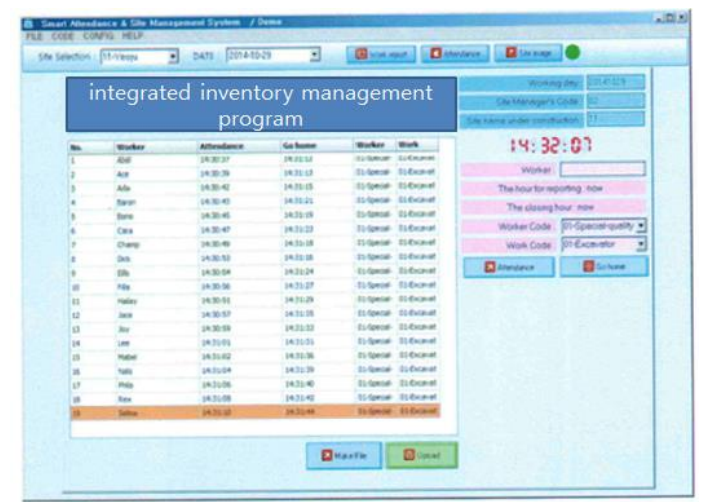

Figure 9. UI Configuration of Integrated Inventory Management

\subsection{UI Configuration and Features for Mobile Device Operation}

Mobile device can be a means of workers receiving work instruction from managers, and it can be a means of communication with the customers allocated to the workers. The worker sends his location information through GPS communication so the manager can very accurately and periodically receive worker task status report, and the manager can do integrated management through mobile device such as giving work instructions. Using the information on delivery inventory list and delivery location allocated to them the worker performs their task. Figure 10 is the app's primary log-in screen and when the worker logs in the worker can check their current location and simple task list. Figure 0 is the initial UI screen that the worker logs in and sends current location. 

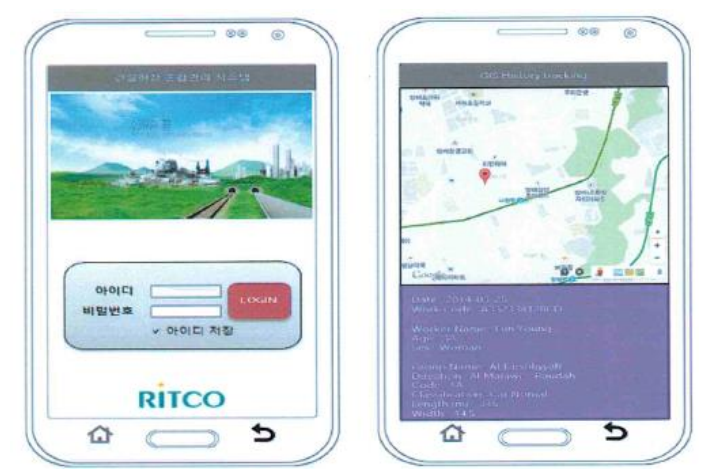

\section{Figure 10. The App's Primary Log-in Screen}

4.3.1. GUI Structure of Mobile Device App : The worker efficiently manages inventory through onsite checklist viewing and recording, and by coordinating tasks with other workers, efficiently performs tasks. The UI composition includes Search methods, search period, search terms, search order, and sorting method, and using the corresponding function, inventory can be searched in various ways. Figure 11 is mobile device app program.
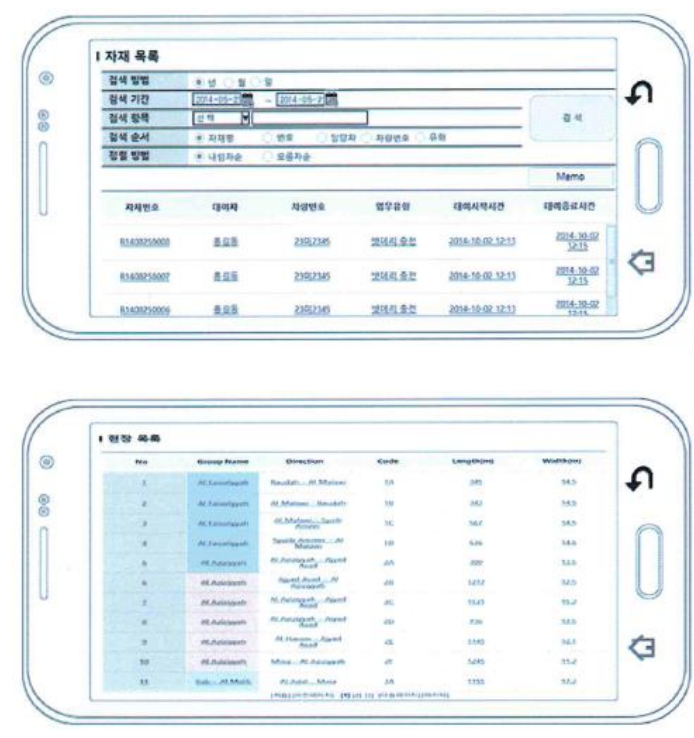

Figure 11. CASE: the Function of Mobile Device App

\section{Conclusion}

In recent years, many services and systems using tracking system have emerged in many different fields. However, the existing tracking systems have many limitations due to the error associated with real-time movement location and the simple system functions.

This paper developed a highly functional, highly efficient smart multiple tracking system for more accurate and reliable logistics transportation while resolving the aforementioned problems.

One of the unique features of this system is to reduce of real-time movement location errors, the most prominent problem of the existing systems, by advancing the system with complex sensors rather than simply tracking location with GPS. Moreover, this system resolved the problem of conducting management task manually after confirming GPS location in the existing systems by allowing for bidirectional communication without any 
restriction.

\section{Acknowledgements}

"This research was supported by the MSIP(Ministry of Science, ICT and Future Planning), Korea, under the C-ITRC(Convergence Information Technology Research Center) (IITP-2015-H8601-15-1008) supervised by the IITP(Institute for Information \& communications Technology Promotion and this research was financially supported by the Ministry of Education (MOE) and National Research Foundation of Korea(NRF) through the Human Resource Training Project for Regional Innovation (No. 2014H1C1A1066414)."

\section{References}

[1] J.-S. Kim, C.-U. Lee, R.-D. Oh, "Development of the Intelligent Facility Monitoring System based on M2M", Advanced Science and Technology Letters, vol.62, (2014), pp.17-20.

[2] S. Son, J. Baik, Y. Baek, "IEEE 802.11-based Power-aware Location Tracking System", Information Security Journal, vol.37B, no. 7, (2012).

[3] K. Oh, J. Song, "A study on the Constrction Materials Management using RFID”, Journal of academiaindustrial technology, vol.11, no.1, (2010), pp. 242-249.

[4] K. Gwangyeol, P. Inhwan I m Yirang, 585 H. Aeran, K. Jinyoung, S. Yoan, "Recent Trends in locationbased services", Information and Communication: Journal of Korea Information and Communications, vol. 28, (2011).

[5] J. Gumin, C. Wansik, "Smart phone location-based services (LBS) technology trends", TTA journal, no. 130, (2010).

[6] D.-C. Hurm, K.-Y. Lee, "Design and implementation of Physical Distribution Management System Using RFID and GPS", Proceeding of The Korean Institute of Maritime Information Communication Sciences (2007), pp.441-444

[7] C.-W. Yu, "Positioning and Management System for Business Logistics by GPS", M.S. Theses, University of Incheon, (2004).

[8] J.-H. Song, K.-S. Oh, C.-H. Han, "The Construction Material Management System using RFID", Korean Society of Design Science, pp. 480-481, (2010).

[9] D.-J. Park and Y.-B. Choi, "Implementation of Ubiquitous Port Operation System Using RTLS", Proceeding of The Korean Institute of Maritime Information Communication Sciences, vol.06, no.12, (2006), pp.128-135.

[10]. D.-C. Hurm, K.-Y. Lee, "Design and implementation of Physical Distribution Management System Using RFID and GPS", Proceeding of The Korean Institute of Maritime Information Communication Sciences, (2007), pp.441-444.

[11] J.-S. Kim, U. Jamshid, D.-H. Kim, C.-U. Lee, R.-D. Oh, "Development of Smart Safety Management System using IoT based assistant equipment for Industrial Fields", vol.23, no. 1, (2015).

[12] U. Jamshid, J.-S. Kim, C.-U. Lee, R.-D. Oh, "The Smart Work Application Service for Contextawareness of Mobile Object based on IoT", Asia Workshop on Convergence Information Technology, (2014).

[13] O. Amon, U. Jamsid, Yusupov, C.-U. Lee, R.-D. Oh, "The Smart Utility Monitoring System for Industrial Safety and Enhancement on the IOT Technology ", Int'l Conference on Smart Media Applications, (2014).

[14] H.-J. Lee, J.-S. Kim, U. Jamshid, M.-K. Han, R.-D. Oh, “The Development of an Intellectual Tracking App System based on IoT and RTLS”, Advanced Science and Technology Letters, vol.85, (2015). 

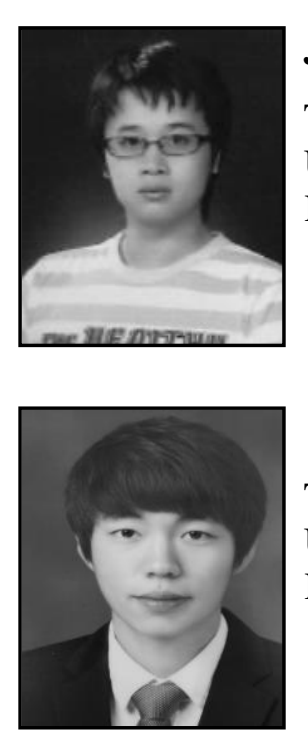

\section{Hak-Jun Lee}

The Department of Software, Master Degree, Korea National University of Transportation, 50 Daehak-Ro, Chung-Ju, Republic of Korea

(e-mail: dorek99@naver.com).

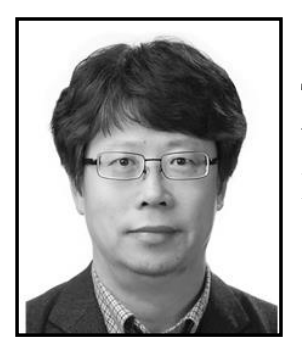

\section{Ryum-Duck Oh}

The Department of Software, Master Degree, Korea National University of Transportation, 50 Daehak-Ro, Chung-Ju, Republic of Korea

(e-mail: rdoh@ut.ac.kr)

1982-1986 earned B.A at Engineering Department, Hongik University, Seoul, Korea. In 1986-1988 earned M.A at Engineering Department, Hongik University, Seoul, Korea. In 1988-1993 earned $\mathrm{PhD}$ at Engineering Department, Hongik University, Seoul, Korea.

1990-present Ryum-Duck Oh worked as a Full Professor in Department of Software, Korea National University of Transportation, Korea. 2001-2002 Dean of Computer and Information Center, Chungju National University, Korea. 2004-2005 Member of Policy Advisory Committee in the Ministry of Education and Human Resourse,Korea. 2009-2010 Dean in Innovation Center for Engineering Education, Chungju National University, Korea. 2010-2012 Dean in College of Advanced Science and Engineering, Chungju National University, Korea. Research Interests are Data Mining, Database, Ubiquitous Sensor Network, Middleware System, and Information Engineering. 